\title{
Influence of alcohol consumption on alveolar bone level associated with ligature-induced periodontitis in rats
}

\section{Daniela Martins de Souza(a) Lucilene Hernandes Ricardo ${ }^{(b)}$ Karla Zanini Kantoski ${ }^{(c)}$ Rosilene Fernandes da Rocha(d)}

(a) PhD, Professor, Department of Dentistry, University of Pindamonhangaba,

Pindamonhangaba, SP, Brazil.

(b) $\mathrm{PhD}$, Professor, Department of Periodontology, School of Dentistry, University of Taubaté, Taubaté, SP, Brazil.

(c) PhD, Professor, Department of Restorative Dentistry, School of Dentistry, Federal University of Santa Maria, Santa Maria, RS, Brazil.

(d) $\mathrm{PhD}$, Professor, Department of Bioscience and Oral Diagnosis, School of Dentistry of São José dos Campos, São Paulo State University, São José dos Campos, SP, Brazil.

\begin{abstract}
Alcohol consumption is a risk indicator for periodontal disease. The purpose of this study was to morphometrically evaluate the influence of alcohol consumption on alveolar bone level associated with ligature-induced periodontitis in rats. Thirty-six female rats (Wistar, 120 days-old) were randomly divided into three groups that received a daily administration of a water diet (control, $\mathrm{n}=12)$, a $10 \%$ alcohol diet $(10 \%$ ethanol, $\mathrm{n}=12)$ or a $20 \%$ alcohol diet $(20 \%$ ethanol, $n=12)$. Four weeks after the onset of the experiment, cotton ligatures were placed around the cervix of the upper right second molar in six rats. The other 6 rats in each group remained unligated. The rats were sacrificed four weeks after ligature placement. The maxillary bones were removed and alveolar bone loss was analyzed by measuring the distance between the cementoenamel junction and the alveolar bone crest at 2 buccal and 2 palatal sites on the upper right second molar. Analyses between the ligated and unligated groups showed that the presence of ligature induced alveolar bone loss $(p<0.05)$. Unligated groups showed no significant differences between each other $(p>0.05)$. In the ligated groups, rats receiving $20 \%$ ethanol showed significantly greater bone loss compared to control rats or rats receiving $10 \%$ ethanol. These results demonstrate that alcohol consumption may increase alveolar bone loss in female rats in a dosedependent manner.
\end{abstract}

Descriptors: Ethanol; Alcoholism; Alveolar bone loss; Periodontitis; Rats.

\section{Corresponding author:}

Daniela Martins de Souza

Av. Engenheiro Francisco José Longo, 777, Jardim São Dimas

São José dos Campos - SP - Brazil CEP: 12245-000

E-mail:danimart.voy@terra.com.br
Received for publication on Apr 14, 2008 Accepted for publication on Aug 22, 2008 


\section{Introduction}

Periodontitis involves the destruction of the supporting structures of the teeth including the periodontal ligament, alveolar bone and gingival tissues. ${ }^{1}$ There are several factors that influence the progression of periodontitis. ${ }^{2,3}$ Social and behavioral factors include cigarette smoking, socioeconomic status, nutritional status, psychological factors and excessive alcohol consumption. ${ }^{2}$

Studies that have evaluated the effects of alcoholism on oral tissues suggest that they may be associated to poor oral hygiene. ${ }^{4,5}$ Evidence exists that persistent alcohol abuse affects periodontal disease severity. ${ }^{6,7}$ In a cross-sectional study involving 13,198 individuals, a moderate but consistent dose-dependent relationship between alcohol consumption and increased severity of periodontal disease was found. ${ }^{7}$ However, other studies on humans have shown no relationship ${ }^{8}$ or a limited relationship ${ }^{9}$ between periodontal disease and alcohol consumption.

Rats have been used to investigate the influence of potential risk indicators/factors and the effects of treatment on periodontal disease. ${ }^{10,11}$ Previous studies have validated the use of morphometric analysis to evaluate alveolar bone loss in ligature-induced periodontitis in rats. ${ }^{10-12}$

Alcohol consumption can affect the bone metabolism directly, since it causes the suppression of tissue formation due to its toxic effect on osteoblastic activity and proliferation. ${ }^{13,14}$

Considering that more studies are necessary to test the hypothesis that alcohol consumption can increase periodontitis development, the aim of this study was to morphometrically evaluate the effect of alcohol consumption on alveolar bone loss in experimental periodontitis in rats.

\section{Materials and Methods Animals}

Thirty six adult female Wistar rats (4 monthsold) weighing an average of $270 \mathrm{~g}$ were used in the study. All the rats were housed under similar conditions and received standard rat chow (Guabi Nutrilador, Mogiana Alimentos, Campinas, SP, Brazil) and different solutions of ethanol (Ecibra, CETUS, Santo Amaro, SP, Brazil), both ad libitum. The In- stitutional Animal Research Committee at the University of São José dos Campos (São Paulo, Brazil) approved the protocol.

\section{Experimental groups}

The rats were randomly distributed into three groups of twelve animals each. Control group: water and rat chow; $10 \%$ ethanol group: rat chow and a liquid diet containing a $10 \%$ ethanol solution; and $20 \%$ ethanol group: rat chow and a liquid diet containing a $20 \%$ ethanol solution.

\section{Experimental procedures}

The rats from the $10 \%$ ethanol and $20 \%$ ethanol groups were subjected to an adaptation period in which the ethanol concentration was increased until it reached experimental concentrations. A solution containing $5 \%$ ethanol was administered to the $10 \%$ ethanol group for 7 days and the $20 \%$ ethanol group received $5 \%$ and $10 \%$ ethanol for 7 days each. After this period, the rats received a diet containing the experimental concentrations for 8 weeks.

After 4 weeks of alcohol consumption, general anesthesia was induced by intramuscular administration with a solution of $13 \mathrm{mg} / \mathrm{kg}$ of $2 \%$ xylazine hydrochloride and $33 \mathrm{mg} / \mathrm{kg}$ of ketamine. In order to induce alveolar bone loss, cotton ligatures were placed around the cervix of the second maxillary molar on the right side in six rats, leaving the other six rats of each group unligated, serving as controls.

After 8 weeks of alcohol administration, the rats were sacrificed, the ligatures were removed and the maxillary bones were fixed in $10 \%$ neutral formalin for $48 \mathrm{~h}$.

\section{Morphometric analysis}

The right maxillae were defleshed and stained with an aqueous methylene blue solution $(1 \%)$ in order to differentiate bone from teeth.

Alveolar bone loss was evaluated morphometrically by measuring the distance between the cementoenamel junction (CEJ) and alveolar bone crest $(\mathrm{ABC})$ at 2 buccal and 2 palatal sites on the upper right second molar in each maxilla (Figure 1). Alveolar bone loss was measured (25 X magnification) using the image analysis system Image Tool v.3.0 


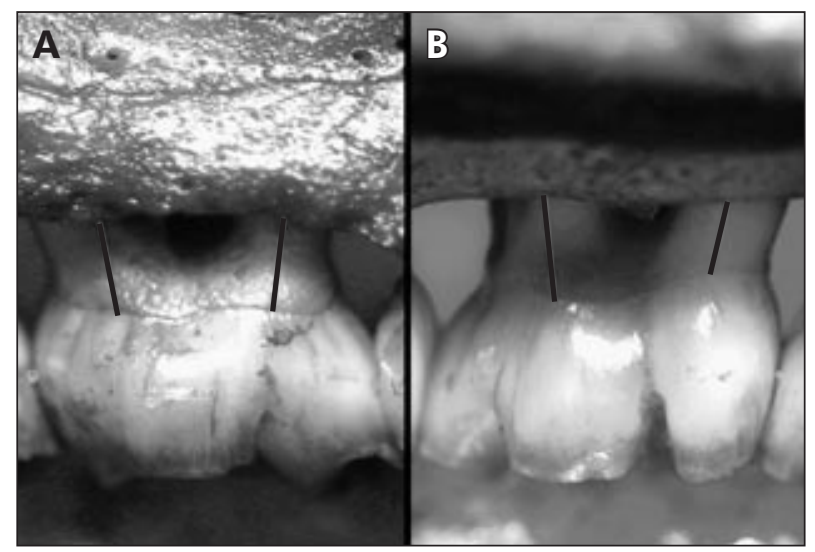

Figure 1 - Photograph of alveolar bone loss evaluated morphometrically by measuring the distance between the cementoenamel junction (CEJ) and alveolar bone crest $(A B C)$ at 2 buccal $(A)$ and 2 palatal $(B)$ sites in each maxilla. The lines indicate the four distances that were measured on each tooth.

(UTHSCSA, San Antonio, TX, USA). All measurements were made along the long axis of the roots of the upper right second molar. The measurements were taken on the 2 buccal and 2 palatal sites, and the bone level was defined as the sum of these four distances. The mean of these measurements was used as the measurement of alveolar bone loss in each group. All measurements were made blind to the group assignment of the rats.

In order to obtain sufficient reproducibility of the molar alignment on the image, the teeth should not overlap each other interproximally, and the buccal cusp tip of each molar should be superimposed on the corresponding lingual cusp tip.

\section{Reproducibility}

One examiner performed double measurements on all the specimens with a one-week interval. Pearson's correlation coefficient was obtained between the two sets of measurements and revealed a very high correlation $(0.98, \mathrm{p}=0.000)$. Paired $t$ test statistics was used and no differences were observed in the mean values used for comparison ( $\mathrm{p}=0.8357)$.

\section{Statistical analysis}

During the experimental period the diet consumed was evaluated as the mean and standard deviation for each group and the results were ex- pressed descriptively. The independent sample $t$ test $(\alpha=0.05)$ was used for comparisons of weight between baseline and final rat body weight in the alcohol groups and control group. The relationship between the consumption of alcohol and rat body weight of the rats was evaluated and the results were expressed descriptively.

For morphometric analysis, the data were expressed as mean and standard deviation $(\mathrm{mm})$, and the independent sample $t$-test $(\alpha=0.05)$ was used for comparisons of alveolar bone loss between ligated and unligated teeth in different rats. Intergroup ANOVA $(\alpha=0.05)$ and the Tukey test for subsequent multiple comparisons $(\alpha=0.05)$ were used to separately determine significant differences in alveolar bone loss among the treatment groups for ligated and unligated rats.

\section{Results Diet and weight analysis}

The $10 \%$ ethanol group consumed an average of $19.71 \pm 2.88 \mathrm{ml} /$ day of alcohol solution $(1.97 \mathrm{ml} /$ day of ethanol) and $12.70 \pm 1.72 \mathrm{~g} /$ day of normal rat chow. The $20 \%$ ethanol group consumed an average of $18.38 \pm 2.59 \mathrm{ml} /$ day of alcohol solution $(3.68 \mathrm{ml} /$ day of ethanol) and $11.53 \pm 2.15 \mathrm{~g} /$ day of normal rat chow.

The systemic effect of alcohol consumption observed by analyzing rat body weight showed that the control rats (baseline: $267.22 \mathrm{~g}$ and final: $281.94 \mathrm{~g}$ ) and $10 \%$ ethanol rats (baseline: $259.67 \mathrm{~g}$ and final: $279 \mathrm{~g}$ ) gained weight (control: $14.72 \mathrm{~g} ; 10 \%$ ethanol: $19.33 \mathrm{~g})$. However, no statistically significant difference was observed between baseline (275.33 g) and final $(274 \mathrm{~g})$ weight in the rats receiving $20 \%$ ethanol in a liquid diet ( $20 \%$ ethanol: $-1.33 \mathrm{~g}$ ).

The relationship between alcohol consumption and rat body weight was evaluated during the study period and showed a consumption of $5.80 \mathrm{~g} / \mathrm{kg} /$ day for the $10 \%$ ethanol group and $10.74 \mathrm{~g} / \mathrm{kg} / \mathrm{day}$ for the $20 \%$ ethanol group.

\section{Morphometric analysis}

Morphometric analysis showed that the cotton ligatures placed around the teeth induced a greater alveolar bone loss $(\mathrm{p}<0.05)$ in ligated teeth com- 


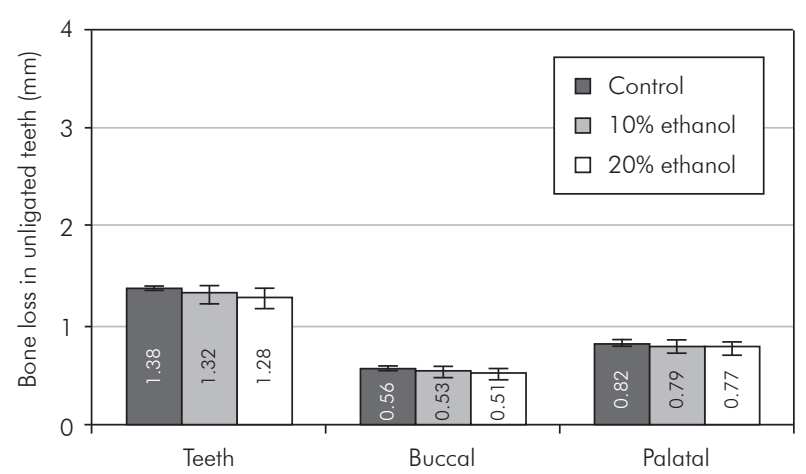

Graph 1 - Mean and standard deviation of alveolar bone loss (mm) for unligated teeth according to each group. *Statistically significant (ANOVA and Tukey test; $p<0.05$ ).

pared to unligated teeth. In unligated teeth, intergroup analysis showed no significant differences between alveolar bone loss values $(p>0.05)$ among the groups (Graph 1). The image depicted in figure 2 is representative of the $20 \%$ ethanol group for the buccal sites of unligated teeth.

When alveolar bone loss was induced, analysis revealed statistically significant differences among the $20 \%$ ethanol group and the other groups $(\mathrm{p}<0.05)$. The study observed significantly higher alveolar bone destruction in the rats receiving $20 \%$ ethanol (teeth: $3.11 \pm 0.58$; buccal sites: $1.63 \pm 0.26$; palatal sites: $1.48 \pm 0.34 \mathrm{~mm}$ ) than in the rats receiving $10 \%$ ethanol (teeth: $2.38 \pm 0.26$; buccal sites: $1.25 \pm 0.10$; palatal sites: $1.13 \pm 0.12 \mathrm{~mm}$ ) and than in the rats receiving water (teeth: $2.27 \pm 0.16$; buccal sites: $1.22 \pm 0.08$; palatal sites: $1.06 \pm 0.11 \mathrm{~mm}$ ) (Graph 2). Figure 3 illustrates the morphometric bone loss in the $20 \%$ ethanol group for the buccal sites of ligated teeth. Figures 4 and 5 are representative of the $10 \%$ ethanol group and control group for the buccal sites of ligated teeth, respectively.

\section{Discussion}

Most studies ${ }^{4,5,7,15-17}$ that reported an association for the influence of alcohol on periodontal disease showed that alcohol consumption has negative effects on periodontal tissues.

Some studies that have evaluated the effects of alcoholism on oral tissues associate developing periodontal problems with poor oral hygiene. ${ }^{4,5}$ However, evidence exists that persistent alcohol abuse af-

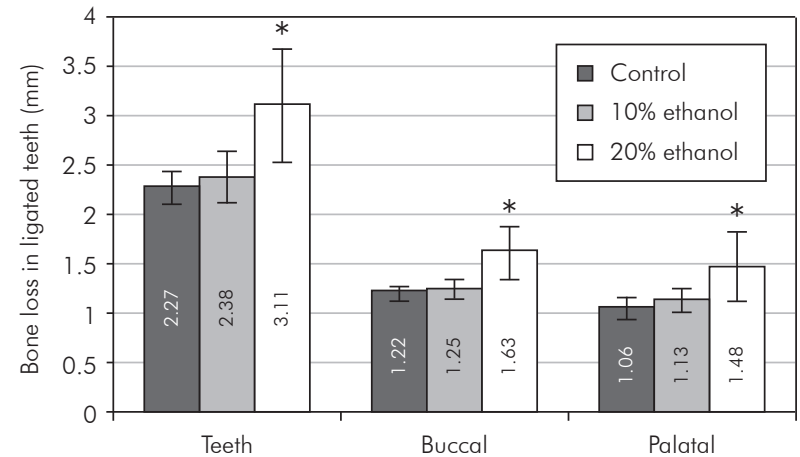

Graph 2 - Mean and standard deviation of bone loss ( $\mathrm{mm}$ ) around ligated teeth, buccal and palatal sites. *Statistically significant (ANOVA and Tukey test; $p<0.05$ ).

fects the severity of periodontal disease, when blood levels of gamma-glutamyl transpeptidase (GGTP), a liver enzyme indicator of alcohol consumption, were determined. ${ }^{6}$

The effects of alcohol on periodontal disease exist and this relation has been explained by biological plausibility through different mechanisms. Chronic alcoholic patients show increased risk for developing severe infection, which appears to be due to an altered immune response. ${ }^{18,19}$ Alcohol has a toxic effect on the liver causing a negative effect on the clotting mechanism. ${ }^{18}$ People who are classified as heavy alcohol drinkers frequently present nutritional disorders resulting from protein and vitamin deficiency. ${ }^{20,21}$ Additionally, ethanol alters the bone metabolism, as demonstrated by dramatic effects on bone in rats. ${ }^{22,23}$ As a consequence of the toxic effects on the liver, bone, immune system and nutrition, alcohol may interfere in the inflammatory response mechanism in periodontal disease.

A population study ${ }^{16}$ that used a self-reported questionnaire regarding alcohol consumption observed a significant relationship between alcohol, gingival inflammation and clinical attachment loss, after controlling for major confounding variables. The study evaluated alveolar bone loss in individuals using an operative program on digitalized radiographic images and observed that alcohol was not significantly related to alveolar bone loss. However, using morphometric methods in rats, the present study observed an association between alcohol consumption and periodontal bone loss. The morpho- 


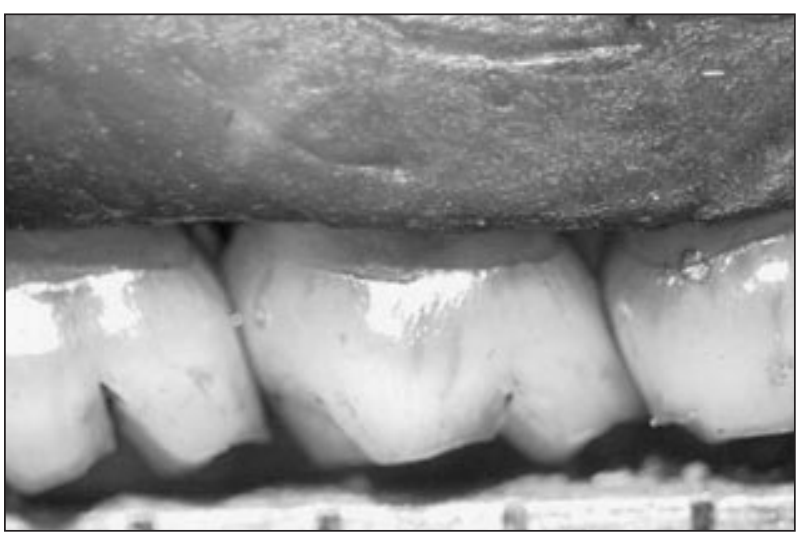

Figure 2 - Photograph representative of the $20 \%$ ethanol group, buccal site of an unligated tooth.

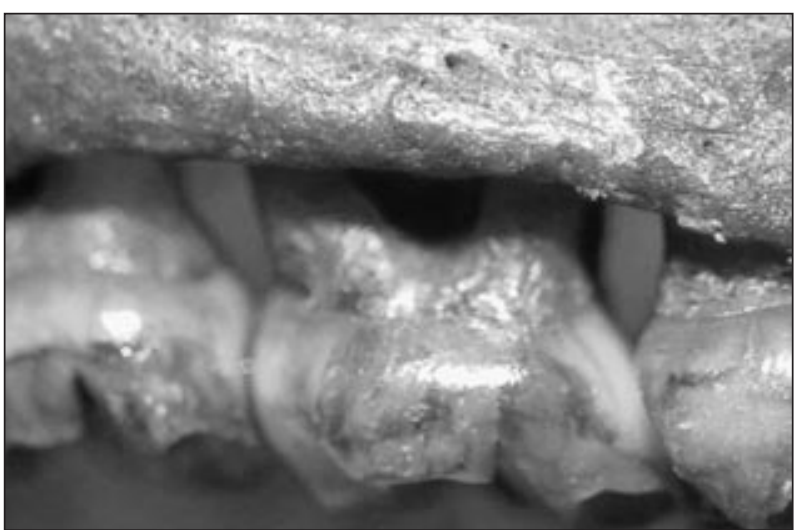

Figure 4 - Photograph illustrating the morphometrically observed bone loss in the 10\% ethanol group, buccal site of a ligated tooth.

metric method is reproducible, has the ability to discriminate between experimental groups ${ }^{24,25}$ and the measurements obtained with it are not significantly different from the histological measurements of alveolar bone level in ligatured rats. ${ }^{26}$

A recent study observed that, in male rats, periodontitis induction led to greater periodontal bone destruction when associated with alcohol intake at concentrations of $10 \%, 20 \%$ and $30 \% .{ }^{27}$ Compared to the present study, these results suggest that the effects of alcohol consumption in male rats may be observed in lower concentration of ethanol than in female rats.

Some studies only examined the effects of alcoholism on oral tissues, ${ }^{4-6}$ without evaluating the influence of different levels of alcohol intake that was

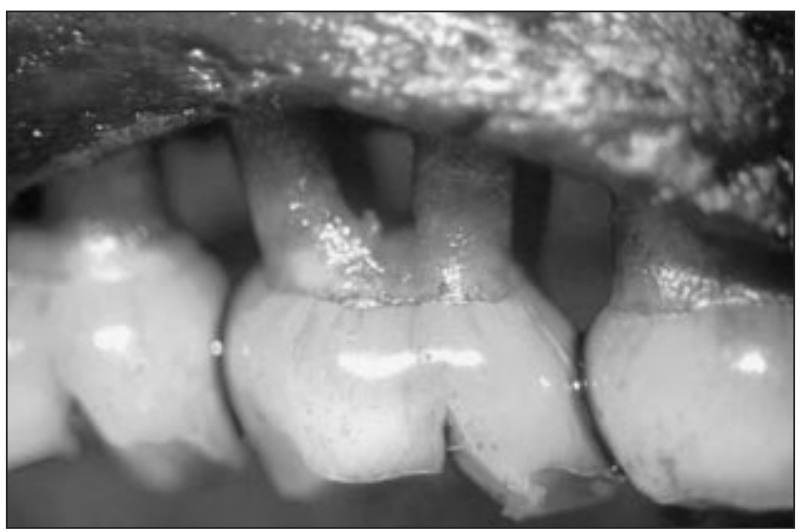

Figure 3 - Photograph illustrating the morphometrically observed bone loss in the $20 \%$ ethanol group, buccal site of a ligated tooth.

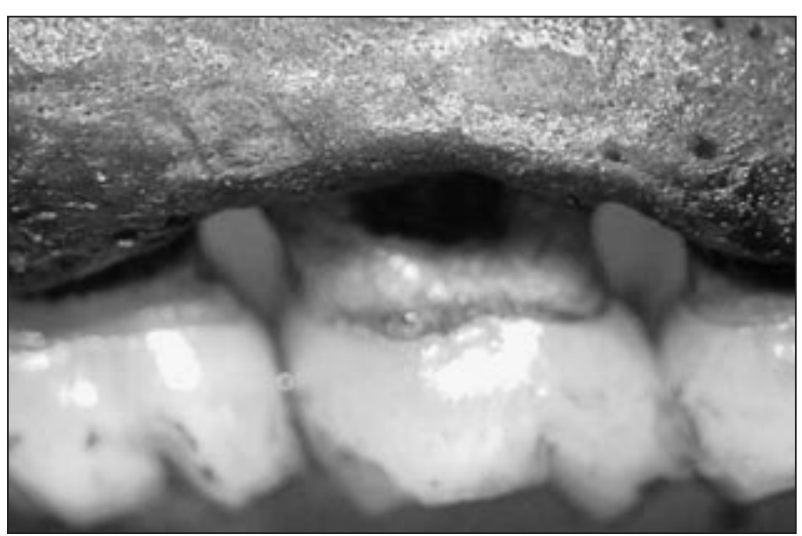

Figure 5 - Photograph illustrating the morphometrically observed bone loss in the control group, buccal site of a ligated tooth.

not associated with a diagnosis of alcoholism. However, the literature contains an important study that found a moderate but consistent dose-dependent relation between alcohol consumption and increased severity of clinical attachment loss in periodontal disease. ${ }^{7}$ In the present study, similar findings were observed associating a dose-dependent effect of alcohol on alveolar bone loss in experimental periodontitis in rats.

A study using cross-section data from a group of older Thai adults found no significant effects of alcohol consumption on periodontal disease severity. ${ }^{8}$ Nevertheless, drinkers were defined as individuals who consumed any type of alcoholic beverage and at least 12 drinks in a 1 -year period. In this study, the frequency and volume of consumption 
were lower than in studies that found a significant interaction between alcohol consumption per week and periodontal disease. ${ }^{7,16}$ This issue of differences of exposures to a determined risk factor was considered by Tezal et al. ${ }^{7}$ (2004) when evaluating the mean clinical attachment loss in drinkers who consumed different quantities, using 5, 10, 15 and 20 drinks/week as cutoff points.

In another study, ${ }^{9}$ Shimazaki et al. (2005) observed that the effect of drinking on periodontal condition was limited to individuals presenting deep periodontal pockets in more than one-third of their teeth. The study did not find a significant relation between drinking and clinical attachment loss, which may be due to the small sample size and more specifically to the low number of drinkers. We suggest that further investigation with a larger sample size of drinkers may well provide more relevant information.

The reduction in human body weight during chronic alcohol consumption is associated with the fact that part of the daily diet calorie intake is provided by the alcoholic beverage. ${ }^{20}$ However, this impact on weight is infrequently observed in rats. ${ }^{22}$ The relationship between alcohol consumption and body weight was evaluated in the present study and revealed a consumption of $5.80 \mathrm{~g} / \mathrm{kg} / \mathrm{day}(10 \%$ etha-

\section{References}

1. Kinane DF. Causation and pathogenesis of periodontal disease. Periodontol 2000. 2001;25:8-20.

2. Nunn ME. Understanding the etiology of periodontitis: an overview of periodontal risk factors. Periodontol 2000. 2003;32:11-23.

3. Stanford TW, Rees TD. Acquired immune suppression and other risk factors/indicators for periodontal disease progression. Periodontol 2000. 2003;32:118-35.

4. Hornecker E, Muuss T, Ehrenreich H, Mausberg RF. A pilot study on the oral conditions of severely alcohol addicted persons. J Contemp Dent Pract. 2003;4(2):51-9.

5. Novacek G, Plachetzky V, Potzi R, Lentner S, Slaviccek R, Gangl A et al. Dental and periodontal disease in patients with cirrhosis: role of etiology of liver disease. J Hepatol. 1995;22(5):576-82.

6. Khocht A, Janal M, Schleifer S, Keller S. The influence of gingival margin recession on loss of clinical attachment in nol group) and $10.74 \mathrm{~g} / \mathrm{kg} /$ day (20\% ethanol group). This relationship in humans is quite different; for example, a $70 \mathrm{~kg}$ individual with a daily intake of five doses (considering $15 \mathrm{~g}$ of ethanol per dose) will maintain a daily alcohol consumption of $75 \mathrm{~g}$; however, this amount represents only $1.07 \mathrm{~g} / \mathrm{kg} /$ day.

This study suggests that ethanol may affect alveolar bone level differently in the presence or absence of experimental periodontitis. Hence, alcohol consumption by itself may not be capable of causing bone loss without ligature-induced periodontitis in rats.

The results of the present study suggest that if alcohol consumption exacerbates alveolar bone loss, the observed effect of drinking on increasing periodontal pocket depth associated with clinical attachment loss may lead to extensive periodontal destruction.

\section{Conclusion}

The results of this study indicate that alcohol consumption increases alveolar bone loss in female rats in a dose-dependent manner. The present results also suggest that alcohol affects periodontal bone loss, thus corroborating this positive relation found in humans.

alcohol-dependent patients without medical disorders. J Periodontol. 2003;74(4):485-93.

7. Tezal M, Grossi SG, Ho AW, Genco RJ. Alcohol consumption and periodontal disease. The third national health and nutrition examination survey. J Clin Periodontol. 2004;31(7):4848.

8. Torrungruang K, Tamsailom S, Rojanasomsith K, Sutdhibhisal $\mathrm{S}$, Nisapakultorn K, Vanichjakvong $\mathrm{O}$ et al. Risk indicators of disease in older Thai adults. J Periodontol. 2005;76(4):55865.

9. Shimazaki Y, Saito T, Kiyohara Y, Kato I, Kubo M, Iida M et al. Relationship between drinking and periodontitis: the Hisayama study. J Periodontol. 2005;76(9):1534-41.

10. Cavaghi J, Soletti AC, Gaio EJ, Rösing CK. The effect of dexamethasone in the pathogenesis of ligature-induced periodontal disease in Wistar rats. Braz Oral Res. 2005;19(4):290-4.

11. Souza DM, Ricardo LH, Kantorski KZ, Rocha RF. Consumo de álcool aumenta o desenvolvimento de periodontite em ratos 
- relativo à perda óssea alveolar. Braz Oral Res. 2007;21(Suppl 1):341.

12. Bjornsson MJ, Velschow S, Stoltze K, Havemose-Poulsen A, Schou S, Holmstrup P. The influence of diet consistence, drinking water and bedding on periodontal disease in SpragueDawley rats. J Periodontal Res. 2003;38(6):543-50.

13. Dyer SA, Buckendahl P, Sampson HW. Alcohol consumption inhibits osteoblastic cell proliferation and activity in vivo. Alcohol. 1998;16(4):337-41.

14. Gonzalez-Calvín JL, Garcia-Sanchez A, Bellot V, Muñoz-Torres M, Raya-Alvarez E, Salvatierra-Rios D. Mineral metabolism, osteoblastic function and bone mass in chronic alcoholism. Alcohol Alcohol. 1993;28(5):571-9.

15. Pitiphat W, Merchant AT, Rimm EB, Joshipura KJ. Alcohol consumption increases periodontitis risk. J Dent Res. 2003;82(7):509-13.

16. Tezal M, Grossi SG, Ho AW, Genco RJ. The effect of alcohol consumption on periodontal disease. J Periodontol. 2001;72(2):183-9.

17. Nishida N, Tanaka M, Hayashi N, Nagata H, Takeshita $\mathrm{T}$, Nakayama $\mathrm{K}$ et al. Association of $\mathrm{ALDH}_{2}$ genotypes and alcohol consumption with periodontitis. J Dent Res. 2004;83(2):161-5.

18. Messingham KAN, Faunce DE, Kovacs EJ. Alcohol, injury, and cellular immunity. Alcohol. 2002;28(3):137-49.

19. Pavia CS, Mothe M, Kavanagh M. Influence of alcohol on antimicrobial immunity. Biomed Pharmacother. 2004;58(2):849.
20. Lieber CS. Relationships between nutrition, alcohol use, and liver disease. Alcohol Res Health. 2003;27(3):220-31.

21. Lieber CS. Alcohol and the liver: metabolism of alcohol and its role in hepatic and extrahepatic diseases. Mt Sinai J Méd. 2000;67(1):84-94.

22. Hefferan TE, Kennedy AM, Evans GL, Turner RT. Disuse exaggerates the detrimental effects of alcohol on cortical bone. Alcohol Clin Exp Res. 2003;27(1):111-7.

23. Hogan HA, Argueta F, Moe L, Nguyen LP, Sampson HW. Adult-onset alcohol consumption induces osteopenia in female rats. Alcohol Clin Exp Res. 2001;25(5):746-54.

24. Klausen B, Evans RT, Sfintescu C. Two complementary methods of assessing periodontal bone level. Scand J Dent Res. 1989;97(2):494-9.

25. Souza DM, Rosa LP, Ricardo LH, Moraes L C, Rocha RF. Avaliação óssea alveolar de Rattus norvegicus por meio dos métodos radiográfico e morfométrico. Cienc Odontol Bras. 2005;8(4):77-84.

26. Fernandes MI, Gaio EJ, Oppermann RV, Rados PV, Rösing CK. Comparison of histometric and morphometric analyses of bone height in ligature-induced periodontitis in rats. Braz Oral Res. 2007;21(3):216-21.

27. Souza DM, Ricardo LH, Prado MA, Prado FA, Rocha RF. The effect of alcohol consumption on periodontal bone support in experimental periodontitis in rats. J Appl Oral Sci. $2006 ; 14(6): 443-7$. 